\title{
Setting Reading Goals and the Ultimate Achievement of Persian EFL Learners in a Computer-Mediated Environment
}

\author{
Amir Toghyani Khorasgani \\ Mohaddeseh Toghyani Khorasgani \\ Payam-e Nour University, Iran
}

\begin{abstract}
This study aimed at investigating the effects of reading goals on L2 reading comprehension in a computer- mediated environment when reading is selfpaced by the learners and students are responsible for their own comprehension. Sixty participants ( 30 males \& 30 females) in three groups of 20 were provided with one of three reading goals: read to comprehend the text, read to take a test, and read to teach the material to another student. Then, the participants were asked to read two passages on a computer screen. A computer program, written in C\#.NET program, presented the text on the screen four lines at a time, and measured the amount of time students would spend on each page initially, how many times students re-read pages, and how much time students would spend re-reading pages. L2 learners' comprehension and learning strategies were measured in three ways: recall of materials, time spent reading each page of the text and time spent re-reading pages, and the number of times pages were reread. Finally, after one month from the first test a posttest was administered to determine which group could remember materials better. The results revealed that recall of materials was significantly greater for the teaching-goal group than the other two groups in both first and second tests. Time spent re-reading was significantly greater for the teaching-goal group as well. These findings suggest that reading goals do have an effect on comprehension and recalling in a computer-mediated environment and students with a different reading goal performed differently while reading passages. This study proposed a way to reduce the burden of teaching on teachers and made the learners responsible for their study.
\end{abstract}

Keywords: reading goals, computer-mediated reading environment, learning, immediate and delayed recall.

\section{INTRODUCTION}

Reasons for learning a second language (L2) vary widely from person to person. Some people may learn an L2 for the pure intrinsic enjoyment that comes with learning a new language while others may learn an L2 in order 
to obtain the extrinsic reward of a better salary (Noels et al., 2000). Reader reads a text to understand its meaning, as well as to put that understanding to use. A person may read a text to learn, to find out information, to be entertained, to reflect or to practice religious issues. The reasons of reading will also affect the way a book is read. We read a dictionary in a different way from the way we read a novel. In the classroom, teachers need to be aware of their students' learning needs, including their goals for reading (Surber, 1992).

As students move beyond the primary grades, the focus of their school lives shifts from learning how to read to using reading to learn. From the middle grades on, students are expected to read and to understand increasingly more difficult materials in an array of content areas. Unfortunately, many students are unable to meet this expectation. For them, reading to learn from content area materials can be a struggle (Biemiller, 1999).

The literature indicates that skilled adult readers rely heavily on reading goals as they apply reading strategies in a purposeful way. As Nunan (2006) stated, when people carry out a reading task they have different purposes in mind, and they use different strategies in accordance with it. They set reading goals, vary reading style depending upon how relevant the text is to those reading goals, read ahead and back in the text to find information relevant to their reading goals, and are aware of their progress toward their reading goals (Pressley \&Afflerbach, 1995; Pressley et al., 1995; Wyatt et al., 1993).

\section{Statement of the Problem}

In the area of reading research, researchers have almost always been preoccupied with the question of how reading can be taught and learned in the best way possible. Teachers always want to teach a reading passage in a way that it is best learned and remembered by students for a long time (Duffy, 2002; Palinscar\& Brown, 1984). Most teachers want to reduce the burden of teaching passages and make students responsible for their learning, so students should make a decision whether or not they understand the text, or whether they need to read and practice on the text more. Students should also use the best reading strategies in relation to their aims. Hall (2001) stated that learning strategies are goal-directed actions used by learners to mediate their own learning. Since the goal of most types of readings is comprehension, it is important for students to make decision about whether or not they comprehend the passages they are reading. If a student decides s/he does not comprehend the passages, s/he must use some strategies to solve this problem by adjusting studying patterns accordingly. Chamot (1987) maintained that learning strategies are techniques, 
approaches, or deliberate actions that students take in order to facilitate learning and recall of both linguistic and content area information.

In current trend of education, especially in distance learning, most students have to use computers and computer programs in their learning in order to be motivated to learn by themselves. Motivated learners are able to set goals for themselves within a time frame. If they recognize that they do not have sufficient knowledge of a subject or the language, they may change their learning strategies according to their goals to match the time available (Hall, 2001). The number of e-books, glossaries, and dictionaries which can be used in computer-mediated environments is rapidly increasing and students need to be familiar with these technologies and the way they are used. The use of these technologies makes it possible for all learners to learn twentyfour hour a day and anywhere if they want to, in other words, whenever they wish to learn.

One problem is arisen here: there is no twenty-four-hour available teacher for students to get help from through their process of reading. So the best solution is to find a good way for the students to take the responsibility of their own learning through the texts and comprehend them as much as possible. Students should self-monitor, self-evaluate, and self-regulate themselves and match language learning strategies with their goals (Hall, 2001). Although students with different goals use different strategies, what is the best goal for reading comprehension in a computer-mediated environment? Reading from the monitor would enable the researchers to pursue learning strategies and clarify their effects on reading comprehension and learning. As Bialystok (1991) stated, "language learning strategies are optional means for exploiting available information to improve competence in a second language" (p. 71). There are few number of studies in relation to the effect of reading goals on the ultimate achievement of EFL learners, the problem of which goal has more effect on reading comprehension and learning and the combination of these two areas with the vast effects of new technologies (computer programs) on the ways of presenting and learning new materials in circumstances that teacher is not easily available for students, and students should take the responsibility of their learning and comprehending the passages they read.

\section{Objectives of the Study}

This study is designed specifically around goal setting in the area of reading comprehension and the focus is on the reading task (i.e., goal) and how it affects immediate recalling, delayed recalling, the time spent on reading and the number of times a reading passage is reviewed. Specifically, this study examines these effects in a computer-mediated environment when the reader has a specific reading goal in mind. In other words, in this study 


\section{ELT Worldwide Vol. 1 No. 1}

comprehension strategies and plans for study patterns and reading behavior are under the control of readers themselves. The researcher merely provides them goals for their reading so the learners are fully responsible for their understanding and learning of what they read.

The study pattern used in this research is the one suggested by Garner and Reis (1993), who found that good comprehenders consistently recognize comprehension problems and use "look-back" strategies to solve them (looking back in the text when a student realizes s/he needs more information from preceding pages). For reading behavior in this study, the time for reading the whole text was calculated. This way of measuring is supported by three previous studies: the work of Monty and Senders (1983) who reported measuring the speed of word and letter identification; the work of Rayner and Pollatsek (1987) who took an interdisciplinary approach to timed reading research which included eye-tracking studies, as well as a cognitive-anatomical approach to studying word recognition; and finally the work of Just and Carpenter (1992) on eye fixations who suggest that longer eye fixations occur when readers are confronted with uncommon words, while they are integrating information from important clauses in the text, and while making inferences at the end of sentences. Although the scope of the present study does not specifically include the detail of eye fixation, longer reading times might suggest differences in reading behavior.

There is also a substantial body of recent literature on goal orientation as a motivational characteristic of the learner. McWhaw\&Abrami (2001) were concerned with the effects of interest in subject matter versus actual rewards (payoffs) for performance on topic recall. While this is an interesting new development in the field, a different sense of the term 'reading goal' is used in the context of this study. The present study has focused on task manipulation more than an abiding characteristic (motivation) of the learners. This focus on task manipulation is important because, in an instructional setting, students are often asked to learn material for which they do not have high interest, and most instructional settings do not provide immediate payoffs. In other words, the present study is more concerned with specific goals for a text where interest may be low to moderate, and the goals are manipulated by the task assigned to the student.

\section{Significance of the Study}

Rapid development in computer technology has had a major impact on language teaching and testing. In 2005 an important global milestone was reached- more than one billion individuals began reading, writing, viewing, and communicating by computer (de Argaez, 2006). To put it differently, more than one-sixth of the world's population is now reading via computer. 
Despite the fact that models and guidelines recommending pedagogically sound practices for incorporating computer-based materials exist (Berry, 2000; Brandl, 2002; Chun \&Plass, 2000), a major concern is that the number of such examples remains limited. A common theme in such studies is the benefit of learners from facilities offering support and assistance in computer learning environments, such as electronic dictionaries, glosses, graphics, and E-books.

One of the new trends of education is related to distance learning in which teachers are not available for students most of the time and learning is selfpaced. Oxford (1990) stated that, learning strategies are specific actions taken by the learner to make learning easier, faster, more enjoyable, more self-directed, more effective, and more transferable to new situations.

The concept of reading goal was discussed in literature review, but few publications have so far explored the effect of reading goals on learning in a computer environment. As Hall (2001) mentioned, students use some learning strategies for their reading and their learning strategies are directly related to their goal. This idea emphasizes this fact that having different reading goals in mind would lead to using different learning strategies. Thus, this research aimed at investigating the effect of reading goals on the students' comprehension and recall of the materials to determine the most effective type of reading goal.

\section{Research Hypotheses}

H01: Different reading goals do not have any significant effect on the immediate-recall of the materials.

H02: Different reading goals do not have any significant effect on the delayed-recall of the materials.

H03: Different reading goals do not have any significant effect on the amount of time spent on reading assigned passages.

H04: Different reading goals do not have any significant effect on the number of times reading passages are reviewed by the EFL learners.

\section{Definition of the Key Terms}

The definition of the specialized terms employed in the thesis is provided below:

Reading goalsare defined as the purpose one has for reading (Covington, 2000'; Pressley \&Afflerbach, 1995).

Learningis defined as adding to one's prior knowledge (Field, 2006).

A computer-mediated environmentis defined as a reading text from a computer monitor (Stakhnevich, 2002; Williams \& Williams, 2000). For this 
76 | ELT Worldwide Vol. 1 No. 1

reason in this study, a computer program especially designed to show the passages in four lines and to assess the number of reading and re-reading of each page and the amount of time spending to read the passages.

Immediate and time-delay recallsare defined as recalling both main and supportive materials (Schmitt, 1990). For the aim of this study, it definesrecalling (both main and supportive materials) immediately after reading of the texts and one month later.

\section{METHOD}

\section{Participants}

For this study, the researcher made use of convenience sampling technique to select the EFL learners studying English at Ahlol-Beyt Language Institute in Isfahan. Wallen\&Fraenkel (2001, p. 137) define convenience sample as "a group of individuals who (conveniently) are available for the study." There were 60 participants ( 30 males \& 30 females) and their ages ranged from 17 to 26, all participants were selected from term 12 and 13 (30 students from each term). They were equally distributed to each group of study according to their level of study and their gender to reduce the effect of participants' proficiency levels and genders. Then they were divided into three groups, 20 each, and each group was assigned a specific goal. In other words, one group was to know the passage, another group was to take a test about the passage, and the other group was to be able to teach the passage. These students were granted extra credit points as an incentive for participating in the study. For entering each of these terms, all students had to take the proficiency test of the English Institute, so all of the participants were homogenized as much as possible.

\section{Instruments}

\section{Reading Task}

The reading task (2000-word) included two different passages, namely, 'How to cope with insomnia' and 'How to read body language'. By the use of two different topics for reading task the effect of background knowledge and familiarity with reading topics tried to be reduced. The criteria for choosing the texts were what Nuttall (1996) offered: 1) suitability of content: interesting and enjoyable materials, 2) exploitability: a text that facilitates the achievement of certain language and content goals, 3) readability: a text with lexical and structural difficulty that will challenge students without overwhelming them, and 4) stimulating topic which increase curiosity of students to read the materials. To cover all these four criteria in this research, reading texts were adopted from a book by Markstein\&Hirasawa (1983), entitle Developing Reading Skills. The reason for using this book was the claim written on its back cover: "this book is tested with native and 
nonnative speaker of English", it is "suitable for self-instruction", it is "appropriate for both ESL and EFL classes" and it has "stimulated topics" which was most appropriate for this study. The reading task was presented in the computer lab on computer monitors. Surber (1994) suggested there was no significant difference between reading texts in print and reading the same text from a computer screen; however, pieces of evidence exist to support the assumption that integrating reading with computer-mediated support improves EFL students' reading skills (Chun \&Plass, 1996; Hong, 1997; Stakhnevich, 2002; Williams \& Williams, 2000). Reading from the monitor would enhance the ability to log reading time per page, re-reading time per page, and the number of visits per page. The text was presented in four-line 'pages' on a computer screen. Reading was self-paced and readers were allowed to scroll forward and backward through the text. The computer program recorded the total amount of time spent on each page (read plus reread) and total amount of time for reading the whole text. Additionally, students were not allowed to take notes to remove the effect of note-taking ability (some of the participates might be familiar with the ways of taking notes meanwhile others may be weak in this part, and this variable could have affected the results of this study).

\section{Distracter Task}

When a student reads a text in an educational setting, the objective is for the student to comprehend and acquire knowledge for future use so the information should be stored in long-term memory and not in short-term memory (Harp, 1999). Field (2006) mentioned that there are some basic features of working memory. One of them is its limited capacity. Therefore, only some of our immediate past experience is retained. Another feature is its temporary nature. For this reason, this is essential for updating moment to moment, and to avoid crowding our mind with irrelevant information. In order to better measure comprehension of the passage, a standard distracter task was administered to eliminate the effect of working memory. An English proficiency test (time filler) was administered to ensure that responding to the test on the passage is not from working memory. It was included fifty classified and standardized test items were adopted from Nelson English language tests, and it was long enough so that participants wouldn't be able to finish them in the allotted time (eight minutes).

\section{Recall Task}

The recall task consisted of a sheet of paper with 20 multiple-choice items and some instructions at the top. Students had to write their goal of study at the related box. Participants were asked to select the appropriate answer for each question. The reason for using the multiple-choice questions was due to varying students' ability in essay type questions and to reduce the irrelevant variable effects (some students might be weaker than others in writing and it 
might affect the study results) and the ease and precise scoring. The whole question sheet included ten questions for each text (both main ideas and detail questions) so each student was to answer all twenty questions. The same procedures were followed after one month with the exception of reading passage (there weren't any passages in the second exam). For the sake of having the same conditions, participants were not allowed to use any notes taken during the reading session of this study to assist with recall. It should be mentioned that the questions for this study were adapted from the mentioned book and as it was claimed on its back cover it tested by native and nonnative speakers of English, but for the purpose of this study the researcher again tested them in a pilot study with 15 students and its validity was confirmed by the experts and its reliability: 0.93 was calculated by using KR-21 formula.

\section{Questionnaire}

The questionnaire only collected demographic information for each of the participants. Questions included: their name, gender, age, their level of studying in the institute, and their reading goals.

\section{Computer Program}

The text was presented to subjects by means of a computer program written in C\#.Net. The program read the passage from the text file and presented the text on the screen in four-line page segments. Subjects were able to move backward and forward through the passage by clicking on the navigation arrows on screen ('Previous' key for moving backward and 'Next' key for moving forward). In this manner, the participants could easily re-read previous passages if they wished, and the program saved their number of readings each page. The program recorded how much time the subjects spent on each four-line page for the first time reading and also a cumulative total of any re-reading time. All data from each participate were saved as a separate file.

\section{Procedure}

First of all, a pilot study was done with 15 students ( 7 females $\& 8$ males). They were divided into three groups of 5 with three different reading goals (reading to teach, reading to know, and reading to take a test) like the main participants of this study. In the first step, they participated in a short warmup section in order to become familiar with the presentation of text and the functions of the keys. Then, they started to read the passages on monitor screen by using the same computer program as the one for the main participants. Finally, after distracter task, they answered the questions. The aim of this pilot study was to ensure the effectiveness of the computer program in recording each participant's data and other facilities. The validity 
of questions and answers had already been confirmed by authorities, but again in the pilot study it was tested by asking students if the questions were related to the passages and if they were satisfied with the choices or not. Fortunately, there was no need for editing and revising the questions, their choices, and the length of passages. The participants for this section were selected from the same level of proficiency but in a different branch of language institute. The only difference between the pilot study and the main study was the number of exams; there was only one (immediate recall) exam for the pilot study.

For the main study, 60 participants were selected from terms 12 and 13. They were divided into three groups, 20 each, and each group was assigned a specific goal and separated from each other according to it. Finally, each participant sat in front of one computer in the computer lab. Participants were given a short online warm-up passage to read in order for them to become familiar with the presentation of text and the functions of the keys. Only two navigation keys were displayed for the participants; one symbol (Next) to advance to the next screen of text, and one symbol (Previous) to go back to the previous screen. Participants were asked to practice using the symbols and were helped until they felt comfortable. A third symbol $(\underline{\underline{\underline{\underline{X}}}})$ was available to terminate the study. Participants were told that they could terminate the study at any time. Then, the participants were told that they would be reading the passages on the computer screen. Each student was given the instruction sheet which provided the reading goal (to understand the passage, or to take a test about the passage, or to be able to teach the passage). After that they were asked to read the passage from the screen at their own pace. Specifically, one group was told to read the passages to understand. A second group was told to read the same materials in order to be prepared for taking test. A third group was told to read the same materials in order to teach. All questions were multiple-choice items and were answered by the researcher in advance.

The passage for this study had 40 pages when presented four lines at a time. In previous studies, when text was presented on a computer, the page size varied from single words at a time (for very short passages less than one print page) to entire screens. The argument has been made (Surber, 1992, 1994) that any unit size is to some extent arbitrary (book pages often end in mid-sentence). The decision of page length in this context became a matter of timing: many short pages would allow for fine-grained reading times; while a smaller number of pages would contain more text with less finegrained reading times.Four-line pages are short enough to provide a better measure of reading time, and also the time for reading is logical. This particular configuration has been used effectively in a number of previous studies (Schoeller\&Surber, 2003; Surber, 1992, 1994). Finally, after one 
month, students took part in another test, but this time there was no reading part and they had to remember what they had read before.

\section{Scoring}

Four sets of data were scored: (1) the recall task in which the participants were asked to recall the materials and select the correct answers for studied topics in the first test; (2) read and re-read times, measuring how much time was spent reading a page the first time, and any time spent re-reading the pages; (3) number of times pages were re-read; and (4) the recall task in which participants were asked to recall the materials for the topics in the second test. To reduce any errors in scoring, each answer sheet was scored twice by the researcher (intra rater reliability). As a result, each participant received one set of scores for recalling materials in each exam.

\section{Recall}

To score the recall task, each of the selected responses was scored with a procedure already developed for the pilot study and was used in similar researches (Schoeller\&Surber, 2003; Surber, 2001). The passage was about two different topics- How to Cope with Insomnia, and How to Read Body Language - to reduce the effect of other unrelated factors and variables. The intent of measuring recall is to investigate what the individual has learned. If learning is the ability to organize information into a schema, recall of both the main ideas and supporting details is important. For this reason in this study, the question included both main ideas and supportive details. There were ten questions for each passage. Recall and selection of answers for these ten questions were scored by using a 0.1 scale. A ' 0 ' was given if the subject was not able to identify the answer and left it blank on the answer sheet or selected the wrong answer; a ' 1 ' was given if the subject could clearly identify and select the correct answer. A total of 10 points were possible for the correct recall and selection of all ten answers. A total of 20 points was possible for the correct recall of materials and selecting the correct answers for both passages.

\section{Time}

The raw time was computed (in milliseconds) by the computer program and was saved by the computer program in separate files for each participant. Students learned how to go to the next and previous texts on computer screen in the warm-up section, and after that students read the instructions which indicated the reading goal. Finally, all times were converted to seconds for the clarity of presentation. There were two features in this part which might have affected the validity. First, it was considered that many participants might fail to follow instructions they had at warm-up section for the first page, and the computed time of that page may be irrelevant to the 
KhorasganiEKhorasgani, Setting Reading Goals and the Ultimate Achievement $\mathbf{8 1}$

goals of this study. Additionally, when the participants finished reading the text, they might have neglected to advance the screen for the last time to the end (although there was on-screen prompt to do so), so the timer would not stop. These extra amounts of time of the first and the last page did not deal with the students' learning and decreased the validity of the test. So for the sake of confidence and valid results, the first and the last page of the passage were left blank and data from these two pages were not included in the results of this study.

\section{Re-reads}

The computer program automatically kept a count of the number of times each page was reread. These re-reads were summed for each individual.

Table 1. Final scores for each participant

\begin{tabular}{|ll|}
\hline 1) & Recall of materials (range $=0-20)$, in the first test \\
\hline 2) & Total time of reading and re-reading each page \\
\hline 3$)$ & Total number of pages re-read \\
\hline 4$)$ & Recall of materials (range $=0-20$ ), in the second test \\
\hline
\end{tabular}

\section{RESULTS}

\section{Data Analysis for the First Hypothesis}

Table 1 tells us that the means of the three groups are different, but it doesn't tell us whether the differences are statistically significant or not. To find out about this, a one-way ANOVA was run. Table2 presents the results of this ANOVA.

Table 2. The Results of the One-way ANOVA for the Immediate Posttest

\begin{tabular}{|c|c|c|c|c|c|}
\hline Source & SS & df & MS & F & Sig. \\
\hline Between Groups & 142.300 & 2 & 71.150 & 13.932 & .000 \\
\hline Within Groups & 291.100 & 57 & 5.107 & & \\
\hline Total & 433.400 & 59 & & & \\
\hline
\end{tabular}

By looking at Table 2, one can easily understand that amount of F-observed is significant $(\mathrm{F}$-observed $=13.932, \mathrm{p}<.000)$. In order to find out the exact place(s) of difference(s), an LSD post hoc test was employed. Table 4.3 depicts the results of this test.

Table 3. The Results of the LSD Post hoc Test for the Immediate Posttest

\begin{tabular}{|l|l|l|l|}
\hline Group & Group & Mean Difference & Sig. \\
\hline \multirow{2}{*}{ reading to teach } & reading to know & $2.65^{*}$ & .000 \\
\cline { 2 - 4 } & reading to take a test & $3.65^{*}$ & .000 \\
\hline
\end{tabular}


$82 \mid$ ELT Worldwide Vol. 1 No. 1

\begin{tabular}{|l|l|l|l|}
\hline reading to know & reading to teach & $-2.65^{*}$ & .000 \\
\cline { 2 - 4 } & reading to take a test & 1.00 & .167 \\
\hline reading to take a test & reading to teach & $-3.65^{*}$ & .000 \\
\cline { 2 - 4 } & reading to know & 1.00 & .167 \\
\hline
\end{tabular}

*.The mean difference is significant at the 0.05 level.

According to Table 3, the following conclusions can be drawn:

1. Group reading to teach outperformed the other two groups, that is, group reading to know and group reading to take a test.

2. Groups reading to know and reading to take a test performed statistically similarly on the immediate posttest; in other words, there is no statistically significant difference between these two group, although the mean of group reading to know is higher than that of group reading to take a test.

Therefore, the first hypothesis can safely be rejected, and it can be claimed that reading goals do have effects on reading performances of the learners.

\section{Data Analysis for the Second Hypothesis}

Table 4. Descriptive Statistics for the Delayed Posttest

\begin{tabular}{|l|c|c|c|c|c|}
\hline \multicolumn{1}{|c|}{ Group } & No. & Minimum & Maximum & Mean & SD \\
\hline Reading to teach & 20 & 14 & 19 & 17.20 & 1.361 \\
\hline Reading to know & 20 & 7 & 16 & 11.85 & 2.519 \\
\hline Reading to take a test & 20 & 6 & 17 & 10.40 & 3.102 \\
\hline
\end{tabular}

It can easily be seen in the above table that the means of the three groups under investigation are different. Another one-way ANOVA was used to understand whether or not the differences are statistically significant. Table 5 gives us this information.

Table 5. The Results of the One-way ANOVA for the Delayed Posttest

\begin{tabular}{|c|c|c|c|c|c|}
\hline Source & SS & df & MS & F & Sig. \\
\hline Between Groups & 513.100 & 2 & 256.550 & 43.194 & .000 \\
\hline Within Groups & 338.550 & 57 & 5.939 & & \\
\hline Total & 851.650 & 59 & & & \\
\hline
\end{tabular}

By checking Table 5, one can see that the amount of F-observed is significant $(\mathrm{F}$-observed $=43.194, \mathrm{p}<.000)$. Once again to find out the exact place(s) of difference(s), another LSD post hoc test was run. Table 6 is devoted to the results of this test.

Table 6. The Results of the LSD Post hoc Test for the Delayed Posttest

\begin{tabular}{|c|l|c|c|}
\hline Group & \multicolumn{1}{|c|}{ Group } & Mean Difference & Sig. \\
\hline \multirow{2}{*}{ reading to teach } & reading to know & $5.35^{*}$ & .000 \\
\cline { 2 - 4 } & reading to take a test & $6.80^{*}$ & .000 \\
\hline
\end{tabular}


KhorasganiEKhorasgani, Setting Reading Goals and the Ultimate Achievement $\mid 83$

\begin{tabular}{|l|l|c|l|}
\hline \multirow{2}{*}{ reading to know } & reading to teach & $-5.35^{*}$ & .000 \\
\cline { 2 - 4 } & reading to take a test & 1.45 & .65 \\
\hline \multirow{2}{*}{ reading to take a test } & reading to teach & $-6.80^{*}$ & .000 \\
\cline { 2 - 4 } & reading to know & -1.45 & .65 \\
\hline
\end{tabular}

*. The mean difference is significant at the 0.05 level.

By examining Table 6, it can be said that in the delayed posttest, too, the group reading to teach outperformed the other two groups- that is, reading to know and reading to take a test- but the other two groups did not have any statistically significant difference in their performances. Therefore, the second hypothesis also can safely be rejected.

\section{Data Analysis for the Third Hypothesis}

Table 7 below shows the descriptive statistics for the amount of time spent on reading and re-reading by each group.

Table 7. Descriptive Statistics regarding the Time Spent Reading and Rereading

\begin{tabular}{|l|c|c|c|c|c|}
\hline \multicolumn{1}{|c|}{ Group } & No. & Minimum & Maximum & Mean & SD \\
\hline Reading to teach & 20 & 70.02 & 75.08 & 73.07 & 1.51558 \\
\hline Reading to know & 20 & 47.22 & 49.28 & 48.34 & .63438 \\
\hline Reading to take a test & 20 & 43.95 & 46.45 & 44.89 & .66117 \\
\hline
\end{tabular}

The above table, too, shows differences among the means of all three groups, but it does not tell us if the differences are significant or not. To do so, a third one-way ANOVA was applied to the results. Table 8 indicates the results of this ANOVA.

Table 8.The Results of the One-way ANOVA for the Time Spent Reading and Re-reading

\begin{tabular}{|c|r|c|c|c|c|}
\hline Source & \multicolumn{1}{|c|}{ SS } & df & MS & F & Sig. \\
\hline Between Groups & 9451.403 & 2 & 4725.702 & 4519.962 & .000 \\
\hline Within Groups & 59.595 & 57 & 1.046 & & \\
\hline Total & 9510.998 & 59 & & & \\
\hline
\end{tabular}

One can easily find out by checking the amount of F-observed (F-observed= 4519.962, $\mathrm{p}<.000$ ) that the differences among the three means are statistically significant, but another post hoc test was needed to determine the exact place(s) of difference(s). Table 9 gives us this information.

Table 9.The Results of the LSD Post hoc Test for the Time Spent for Reading and Re-reading

\begin{tabular}{|l|l|c|c|}
\hline \multicolumn{1}{|c|}{ Group } & \multicolumn{1}{c|}{ Group } & Mean Difference & Sig. \\
\hline \multirow{2}{*}{ reading to teach } & reading to know & $24.73^{*}$ & .000 \\
\cline { 2 - 4 } & reading to take a test & $28.18^{*}$ & .000 \\
\hline reading to know & reading to teach & $-24.73^{*}$ & .000 \\
\hline
\end{tabular}




\begin{tabular}{|l|l|c|c|}
\hline & reading to take a test & $3.45^{*}$ & .000 \\
\hline \multirow{2}{*}{ reading to take a test } & reading to teach & $-28.18^{*}$ & .000 \\
\cline { 2 - 4 } & reading to know & $-3.45^{*}$ & .000 \\
\hline
\end{tabular}

*. The mean difference is significant at the 0.05 level.

The following conclusions can be reached at by considering Table 9:

1. Group reading to teach outperformed the other two groups, that is, group reading to know and group reading to take a test.

2. Groups reading to know outperformed group reading to take a test Therefore, the third hypothesis can also be rejected, and it can be claimed that reading goals do have effects on the amount of time spent on reading and re-reading the texts by the learners.

\section{Data Analysis for the Fourth Hypothesis}

A computer software was implemented to measure the number of times each page was read. Table 10 presents the descriptive statistics for this measurement.

Table10. Descriptive Statistics for the Number of Times Each Page Was Read

\begin{tabular}{|l|c|c|c|c|c|}
\hline \multicolumn{1}{|c|}{ Group } & No. & Minimum & Maximum & Mean & SD \\
\hline Reading to teach & 20 & 2.11 & 4.01 & 3.01 & .40099 \\
\hline Reading to know & 20 & 1.23 & 2.09 & 1.73 & .24624 \\
\hline Reading to take a test & 20 & 1.17 & 2.11 & 1.69 & .30529 \\
\hline
\end{tabular}

The table indicates mean differences among the three groups involved in this study. A fourth one-way ANOVA was needed to determine whether or not these differences are meaningful. Table 11 is devoted the results of this ANOVA.

Table 11. The Results of the One-way ANOVA for the Number of Times

Each Page Was Read

\begin{tabular}{|c|c|c|c|c|c|}
\hline Source & SS & df & MS & F & Sig. \\
\hline Between Groups & 22.538 & 2 & 11.269 & 107.450 & .000 \\
\hline Within Groups & 5.978 & 57 & .105 & & \\
\hline Total & 28.516 & 59 & & & \\
\hline
\end{tabular}

The results of this last ANOVA also shows a significant amount of Fobserved (F-observed $=107.450, \mathrm{p}<.000)$. In other words, the three groups performed differently with regard to the number of times each page was read. Here once again, it is necessary to find out about the exact place(s) of difference(s); therefore still another LSD post hoc test was used. Table 12 indicates the results of this test.

Table 12.The Results of the LSD Post hoc Test for the Number of Times Each Page Was Read 
KhorasganiEKhorasgani, Setting Reading Goals and the Ultimate Achievement $\mid 85$

\begin{tabular}{|l|l|c|c|}
\hline \multicolumn{1}{|c|}{ Group } & \multicolumn{1}{|c|}{ Group } & Mean Difference & Sig. \\
\hline \multirow{2}{*}{ reading to teach } & reading to know & $1.28^{*}$ & .000 \\
\cline { 2 - 4 } & reading to take a test & $1.32^{*}$ & .000 \\
\hline \multirow{2}{*}{ reading to know } & reading to teach & $-1.28^{*}$ & .000 \\
\cline { 2 - 4 } & reading to take a test & .04 & .648 \\
\hline \multirow{2}{*}{ reading to take a test } & reading to teach & $-1.32^{*}$ & .000 \\
\cline { 2 - 4 } & reading to know & -.04 & .648 \\
\hline
\end{tabular}

*. The mean difference is significant at the 0.05 level.

According to Table 12, the results here are exactly the same as those of the first hypothesis; That is, the number of time each page was read by group reading to teach is more than those of the other two groups. However, the other two groups, that is, reading to know and reading to take a test, did not have any significant difference in this respect. Therefore, the fourth hypothesis is rejected, too, and it can be said that the goal of reading influences the number of times a passage is read. The next chapter presents the discussion of the results in detail.

In summary, regarding to the immediate recall tests according to the statistics the students with knowing goal and testing goal acted statistically the same and students with teaching goal outperformed other two groups. For the delay recall tests, students with teaching goal outperformed other two groups and the other two groups (students with knowing goal and testing goal) did not have any statistically significant difference in their performances. Regarding to the amount of spending time on reading and rereading assigned passages all three groups acted differently, group reading to teach outperformed the other two groups and groups reading to know outperformed group reading to take a test. Finally, regarding to the number of time each page was read and reread by each group data analysis proved that reading to teach group reread more than those of the other two groups and other two groups (reading to know and reading to take a test) did not have any significant difference in this respect.

\section{DISCUSSION, CONCLUSION AND IMPLICATIONS}

One of the problems currently facing language teachers is the problem of specifying factors to improve learning and direct students toward selfreading and self-study. The findings of this thesis suggest using of different goals to motivate students for achieving pre-established instruction aims, as Covington (2000) introduced goal setting as part of motivational tools in the article Goal Theory, Motivation, and School Achievement.

Individuals read for different purposes, and the ability to comprehend written text is important for effective learning. School learning is commonly assessed by having students read for comprehension. From a Vygotskian perspective, reading comprehension involves readers' constructing an 
impression of a writer's intention by using aspects of their existing knowledge. It is an active participatory process in which progressive representations of the text, developed by the text-induced linking, are matched against aspects of the existing knowledge and are evaluated for consistency through semantic monitoring and are summarized (Munro, 1996).

This study used a new program to study students' reading behaviors and comprehension with different reading goals in mind. For each student this program saved his/her reading behaviors (amount of time spent on passages and the number of times reading and re-reading each page) in a separate file. Regarding the immediate recall tests, it should be mentioned that the students with knowing goal and testing goal acted the same. This finding is consistent with that of another study in which the students tended to expect to be testedin experiments (Orne, 1962). Because of this, the goals reading to test and reading to know may have essentially the same goals for those participants so the failure to find a difference between testing goal and the knowing goal is not a serious mystery. Therefore, of the three reading goal groups participated in this study, the teaching goal group did significantly better in recalling materials than the testing and knowing goal groups. This study also proved the amount of forgetting for students with the teaching goal is the least among all three groups, since they could remember more materials than other two groups could. In this study participants were responsible for their own learning since they had the opportunity to go back and forth through the passages and decided whether they learnt them or not. So this study reduced the burden of teaching on teachers and made the learners responsible for their study; it is toward the distance-learning trend instruction in which teachers are not available most of the time.

This study reduced the burden on the classroom teachers because students were responsible for their learning and they were aware that they were decision makers for their learning; they should make a decision if they understand the text or not, or if they need practice to read the text. Students also had to use the best reading strategies related to their aims. This study is toward the new trend of using technologies in teaching and learning and distance learning. In distance learning, students are responsible for their own learning. They should think what is important and needs more concentration, and pay attention to their aim of study. In addition, this computer-mediated reading program enables students to monitor both their reading and comprehension; it allows students to go back and forth through texts and stop anywhere they think it is necessary.

Apart from the reported enthusiasm for using computers, the realization that "technology is essentially impotent without creative and imaginative application" (Bailey, 1996, p. 73) was ever strong in the nineties. Language 
KhorasganiEKhorasgani, Setting Reading Goals and the Ultimate Achievement $\mid 87$

educators argued, "it is how we use these tools that will ultimately affect our students and the foreign language curriculum" (Armstrong \&Yetter-Vassot, 1994, p. 476).

For further studies, researchers can use this way of research for other skills, like listening, and survey the different outcomes for each group. For example, after listening to a text by computer, the researcher can evaluate recalling of key words, main ideas, and topics of listening text in both introspection (immediate recall) and retrospection (time-delay recall) and also the number of times each group listen and re-listen to the script. A researcher also can conduct the same procedure and reading goals like those of this study with six groups (three non-native groups and three native groups) and evaluate the differences between these two pairs of groups.

\section{REFERENCES}

Armstrong, K. M.\&Yetter-Vassot, C. (1994).Transforming teaching through technology.Foreign Language Annals, 27(4), 475-486.

Bailey, J. (1996). Teaching about technology in the foreign language class.Foreign Language Annals, 29(1), 82-90.

Berry, L. H. (2000). Cognitive effects of web page design. In B. Abbey (Ed.), Instructional and cognitive impacts of Web-based education (pp. 41-55). London: Idea Group Publishing.

Bialystok, E. (1991). A theoretical model of second language learning.Language Learning, 28, 69-83.

Biemiller, A. (1999). Language and reading success. Cambridge, MA: Brookline Books.

Brandl, K. K. (2002). Integrating internet-based reading materials into the foreign language curriculum: from teacher to student-centered approaches. Language Learning \& Technology, 6(3), 87-107.

Chamot, A. (1987). The learning strategies of ESL students.In A. Wenden\& J. Rubin (Eds.), Learner strategy in language learning (pp. 71-83). Englewood Cliffs, NJ: Prentice Hall, Inc.

Chun, D. M., \&Plass, J. L. (1996).Facilitating reading comprehension with multimedia.System, 24, 503-519.

Chun, D. M., \&Plass, J. L. (2000).Networked multimedia environments for second language acquisition. In M. Warschauer\& R. Kern (Eds.), Network-based language teaching: Concepts and practice (pp. 151170). New York: Cambridge University Press.

Covington, M. V. (2000). Goal theory, motivation, and school achievement: 
An integrative review. Annual Review of Psychology, 51, 171-200.

De Argaez, E. (January, 2006). Internet world stats news, 14.Retrieved December 15, 2006 from, http://www.internetworldstats.com/pr/edi014.htm\#3

Duffy, G. G. (2002). The case for direct explanation of strategies. In. C. C. Block \& M. Pressley (Eds.), Comprehension instruction: Researchbased best practices (pp. 28-41). New York: Guilford.

Field, J. (2006). Psycholinguistics: A resource book for students. Routledge: Routledge English Language Introductions.

Garner, R., \& Reis, R. (1993). Monitoring and resolving comprehension obstacles: An investigation of spontaneous text lookbacks among upper-grade good and poor comprehenders. Reading Research Quarterly, 16, 569-582.

Hall, J. K. (2001). Methods for teaching foreign languages. Upper Saddle River, NJ: Prentice-Hall, Inc.

Harp, B. (1999).Developing strategic readers: The key to comprehension.Reading Forum New Zealand, 1, 6-13.

Hong, W. (1997).Multimedia computer-assisted reading in business Chinese. Foreign Language Annals, 30, 335-344.

Just, M.A., \& Carpenter, P. A. (1992). A capacity theory of comprehension: Individual differences in working memory. Psychological review, 99, 122-149.

Markstein, L. \&Hirasawa, L. (1983).Developing reading skills ( $2^{\text {nd }}$ ed.). Massachusetts: Newbury House Publisher, INC.

McWhaw, K.\&Abrami, P. C. (2001). Student goal orientation and interest: Effects on students' use of self-regulated learning strategies. Contemporary Educational Psychology, 26, 311-329.

Monty, R. A., \& Senders, J. W. (Eds.).(1983). Eye movement and psychological processes. Hillsdale, NJ: Erlbaum.

Munro, J. (1996). Teaching reading strategies. Hawthorn: Australia.

Noels, K. A., Pelletier, L. G., Clément, R., \&Vallerand, R. J. (2000). Why are you learning a second language? Motivational orientations and self-determination theory.Language Learning, 50, 57-85.

Nunan, D. (2006). Second language teaching \& learning. Boston: Thomson Publishing Company.

Nuttal, C. (1996).Teaching reading skills in a foreign language ( $2^{\text {nd }}$ ed.). Oxford: Heinemann. 
KhorasganiEKhorasgani, Setting Reading Goals and the Ultimate Achievement 89

Orne, M. T. (1962). On the social psychology of the psychological experiment: With particular reference to the demand characteristics and their implications. American Psychologist, 17, 776-783.

Oxford, R. L. (1990). Language learning strategies: What every teacher should know. New York: Newbury House.

Palincsar, A. S. \& Brown, A. L. (1984).Reciprocal teaching of comprehension-fostering and comprehension-monitoring strategies.Cognition and Instruction, 2, 117-175.

Pressley, M.\&Afflerbach, P. (1995).Verbal protocols of reading: The nature of constructively responsive reading. Hillsdale, NJ: Erlbaum

Pressley, M., Brown, R., El-Dinary, P. B., \&Afflerbach, P. (1995). The comprehension instruction that students need: Instruction fostering constructively responsive reading. Learning Disabilities Research and Practice, 10, 215-224.

Rayner, K. \&Pollatsek, A. (1987). Eye movements in reading: A tutorial review. In M. Coltheart (Ed.), Attention and performance XII: The psychology of reading. Hillsdale, NJ: Erlbaum

Schmitt, M. C. (1990). A questionnaire to measure children's awareness of strategic reading processes. The Reading Teacher, 43(7),454.

Schoeller, B. A.\&Surber, J. R., (2003).Using think-aloud strategies to gain insight on how importance isdetermined by readers of text. Unpublished manuscript, University of Wisconsin-Milwaukee.

Stakhnevich, J. (2002). Reading on the web: Implications for ESL professionals. The Reading Matrix, 2(2).

Surber, J. R. (1992). The effect of test expectation, subject matter, and passage length on study tactics and retention.Reading Research and Instruction, 31, 32-40.

Surber, J. R. (1994). Identification of important elements in lengthy instructional text.Reading Research and Instruction, 33, 175-186.

Surber, J. R. (2001). Effect of topic label repetition and importance on reading time and recall of text.Journal of Educational Psychology, 93, 279-287.

Wallen, N. E.\&Fraenkel, J. R. (2001).Educational research: A guide to the process. Mahwah, NJ: Lawrence Erlbaum Associates.

Williams, H. S., \& Williams, P. N. (2000).Integrating reading and computers: an approach to improve ESL students reading skills.Reading Improvement, 37(3), 98-100. 
90 ELT Worldwide Vol. 1 No. 1

Wyatt, D., Pressley, M., El-Dinary, P., Stein, S., Evans, P., \& Brown, R. (1993). Comprehension strategies, worth and credibility monitoring, and evaluations: Cold and hot cognition when experts read professional articles that are important to them. Learning and Individual Differences, 5, 49-72. 